\title{
Alfabetização de jovens e adultos no Brasil: uma face da História nas produções acadêmicas no final do Século XX
}

\author{
Youth and adult literacy in Brazil: \\ a face of History in the academic productions in the late 20th century
}

Alfabetización de jóvenes y adultos en Brasil:

una cara de la Historia en las producciones académicas a finales del Siglo XX

Juliano Guerra Rocha

Secretaria do Estado de Educação de Goiás (Brasil)

https://orcid.org/0000-0001-7101-0116

http://lattes.cnpq.br/1944535179478135

professorjulianoguerra@gmail.com

Ilsa do Carmo Vieira Goulart

Universidade Federal de Lavras

https://orcid.org/0000-0002-9469-2962

http://lattes.cnpq.br/2333309094936325

ilsa.goulart@ufla.br

\section{RESUMO}

Tomando as produções acadêmicas como fonte histórica, esse estudo tem por objetivo analisar e compreender a história da alfabetização de jovens e adultos no Brasil a partir dos discursos acadêmicos produzidos no período de 1978 a 2000. A demarcação temporal inicial, 1978, se justifica por ter ocorrido nesse ano a defesa da primeira pesquisa de Dissertação de Mestrado identificada sobre alfabetização de adultos vinculada a um programa de pósgraduação brasileiro, e a final, o ano de 2000, para situarmos este artigo no âmbito do século $\mathrm{XX}$. Desse modo, apresentamos um panorama de como as pesquisas brasileiras abordaram o tema alfabetização de jovens e adultos antes e depois da promulgação da Lei de Diretrizes e Bases da Educação Nacional n. ${ }^{\circ}$ 9394, de 1996, momento em que, no Brasil, a Educação de Jovens e Adultos foi reconhecida como modalidade de ensino.

Palavras-chave: Alfabetização de adultos. Educação de Jovens e Adultos. Historicidade. 


\begin{abstract}
Taking the academic productions as historical source, hhis study aims to analyze and understand the history of adult and youth literacy in Brazil, from the academic discourses produced in the period from 1978 to 2000. The initial time demarcation, 1978, for being in this year, the first dissertation identified research on adult literacy, inked to a Brazilian graduate program, and the year 2000 to put this article in the context of the 20th century. Thus, we present an overview of how the Brazilian research addressed the theme of youth and adult literacy, before and after the enactment of the Lei de Diretrizes e Bases da Educação Nacional n. ${ }^{\circ}$ 9394, of 1996, moment in Brazil, education of young people and Adults was recognized as teaching mode.
\end{abstract}

Keywords: adult literacy. Adult and youth education. Historicity.

\title{
RESUMEN
}

Tomando las producciones académicas como fuente histórica, este estudio pretende analizar y entender la historia de la alfabetización de adultos y jóvenes en Brasil, de los discursos académicos producen en el período 1978-2000. La demarcación del tiempo inicial, 1978, por ser en ese año, el primer identificado tesis sobre alfabetización de adultos, vinculada a un programa graduado brasileño, y el año 2000 a poner este artículo en el contexto del siglo XX. Así, presentamos un resumen de cómo la investigación brasileña abordó el tema de la juventud y la alfabetización de adultos, antes y después de la promulgación de la Lei de Diretrizes e Bases da Educação Nacional n. ${ }^{\circ}$ 9394, de 1996, momento en Brasil, la educación de jóvenes y adultos fue reconocida como modo de enseñanza.

Palabras clave: alfabetización de adultos. Educación de adultos y jóvenes. Historicidad 


\section{Introdução}

Esse trabalho, ao tomar como mote investigativo as produções acadêmicas do final do século XX que tematizaram a alfabetização de jovens e adultos, caracteriza-se por uma "operação histórica", que, segundo Certeau (2010, p. 93), consiste em "recortar o dado segundo uma lei presente, que se distingue do seu 'outro' (passado)", com certo distanciamento da situação em que foi emitida ou divulgada, no caso, a demarcação temporal estabelecida entre os anos de 1978 a 2000, que balizam o recorte desta pesquisa. Isso deve-se ao fato de, para Certeau (2010, p. 93), a operação histórica ter duplo efeito: um refere-se ao ato de que, ao se historiar o presente, ao trazer para a discussão situações vividas, de modo específico, nesse texto opta-se pelos temas pesquisados sobre a EJA, em que se instaura um "lugar próprio", ou seja, um lugar de pesquisas e de produções acadêmicas; outro instaura-se no ato de "representar aquilo que falta", sabendo das limitações de se exprimir o que está ausente, como dados ou documentos, disponibilização de produções na íntegra, situações frente às quais se depara com o desafio de trabalhar com os "não-ditos".

Ao considerar a alfabetização de jovens e adultos como área de discussão acadêmica, constata-se um distanciamento em relação à produção avolumada de discussões que compreendem o processo de alfabetização de crianças. Os estudos sobre a história da alfabetização no Brasil têm sua origem e, ainda hoje, sua tradição de pesquisa marcados especialmente nos aspectos do ensino para crianças. Entretanto, ao falarmos em alfabetização, a concebemos como o ensino inicial de leitura e escrita, não restrito a um público específico ou faixa etária. É um conceito e um processo amplo e aberto, já que pode ocorrer a qualquer momento da vida. Dessa maneira, a história da alfabetização abriga pesquisas sobre as crianças, jovens, adultos e idosos.

Do desnível de acúmulo de pesquisas e estudos sobre a educação de crianças, houve durante décadas, na história da alfabetização de jovens e adultos do Brasil, uma lacuna tanto de referências teóricas quanto metodológicas que subsidiassem as propostas didáticas e as discussões a respeito da alfabetização de jovens e adultos, por isso o embasamento subscrevia-se a partir das discussões da alfabetização de crianças. O próprio material didático e as práticas educativas disponibilizadas aos públicos jovem e adulto não se diferenciavam daqueles dirigidos às crianças. Sabe-se, a partir dos estudos históricos sobre a EJA, que essa modalidade conquistou, mais recentemente, exigências específicas para a produção de material didático e para a formação daqueles que vão atuar com alunos jovens e adultos. Alguns marcos desse percurso foram: a homologação no Conselho Nacional de Educação do Parecer n. ${ }^{\circ} 11$ de 10 de maio de 2000, que tratava das Diretrizes Curriculares Nacionais para Educação de Jovens e Adultos (BRASIL, 2000); e a publicação, em 2010, do edital específico para escolha de livros didáticos destinados aos alunos da EJA, no âmbito do Programa Nacional do Livro e do Material Didático (PNLD) ${ }^{1}$

Nesse trabalho, portanto, a história da alfabetização de jovens e adultos do Brasil será reconstituída a partir de uma análise das produções acadêmicas tomadas como fonte histórica. $\mathrm{O}$ estudo tem por objetivo analisar e compreender a história da alfabetização de jovens e adultos no Brasil a partir dos discursos acadêmicos produzidos no período de 1978 a 2000 . A demarcação temporal inicial de 1978 se justifica por ter ocorrido nesse ano a defesa da primeira pesquisa de Dissertação de Mestrado identificada dentro dos limites dessa pesquisa sobre alfabetização de adultos, vinculada a um programa de pós-graduação brasileiro, e a final, o ano de 2000, para situarmos esse artigo no âmbito do século XX.

A pesquisa foi realizada a partir do levantamento das teses e dissertações nos repositórios da Biblioteca Digital do IBICT (Instituto Brasileiro de Informação em Ciência e Tecnologia) e do

${ }^{1}$ O Programa Nacional do Livro Didático para Educação de Jovens e Adultos (PNLD EJA) foi criado pela Resolução n. ${ }^{\circ}$ 51, de 16 de setembro de 2009, do Fundo Nacional de Desenvolvimento da Educação (BRASIL, 2009). 
Banco de Teses e Dissertações da Capes (Coordenação de Aperfeiçoamento de Pessoal de Nível Superior). Desse modo, fizemos um panorama de como as pesquisas brasileiras abordaram o tema alfabetização de jovens e adultos, antes e depois da promulgação da Lei de Diretrizes e Bases da Educação Nacional (LDBEN) n. ${ }^{\circ}$ 9.394, de 20 de dezembro de 1996 (BRASIL, 1996), momento em que, no Brasil, a Educação de Jovens e Adultos foi reconhecida como modalidade de ensino, destinada a todos os que não tiveram acesso ou não concluíram a educação básica na idade própria. Até então, o atendimento escolar ao aluno adolescente e adulto era nomeado de Ensino Supletivo, como exarava a Lei n..$^{\circ}$ 5.692, de 11 de agosto de 1971, que fixava as Diretrizes e Bases para o Ensino de $1^{\circ}$ e $2^{\circ}$ graus (BRASIL, 1971) $)^{2}$.

Da perspectiva do campo das políticas públicas de EJA às discussões no campo científico produzidas pelas universidades brasileiras, que se constituíram, historicamente, pelo tripé do ensino, pesquisa e extensão, esse artigo focaliza a questão da pesquisa, assumindo as teses e dissertações como resultados de investigações escritas, exclusivamente, no bojo de uma instituição de ensino superior. Diante disso, com intuito de aproximar-se das discussões em torno da história e memória da EJA, nas universidades, a análise empreendida nesse texto se deu a partir das seguintes problematizações: como a universidade brasileira, especialmente em suas pesquisas, abordou o tema da alfabetização de jovens e adultos no final do século XX? O que as teses e dissertações produzidas entre 1978 e 2000 revelam sobre a história da alfabetização de jovens e adultos, bem como da EJA, no Brasil? Para tanto, partimos da hipótese de que a temática da alfabetização de jovens e adultos têm um lugar específico e plural nas pesquisas produzidas nas universidades brasileiras no século XX.

Ao final do texto apontamos que, ao fazer esse balanço da produção acadêmica pretendemos não somente analisar as temáticas e abordagens priorizadas ao longo de três décadas, mas, ao mesmo tempo, evidenciar as lacunas que necessitam ser investigadas para compreensão histórica da persistência do fenômeno do analfabetismo no Brasil.

\section{As produções acadêmicas brasileiras sobre a EJA}

Ao subsidiar o estudo sobre a temática da alfabetização de jovens e adultos, tem-se na operação historiográfica a necessidade de compreender, conforme Certeau (2010, p. 66), a relação construída na combinação de um "lugar social", de "práticas científicas" e de uma "escrita", de modo que o "lugar", que no caso se referencia às produções acadêmicas, ao "procedimento de análise", à escolha metodológica, à realização de uma pesquisa bibliográfica e à "construção de um texto", resulta na produção desse artigo. Assim, articulamos um cruzamento das escritas produzidas sobre EJA.

Nesse campo de produção destacam-se três grandes grupos de produção acadêmica que tematizam sobre a EJA. No primeiro grupo observa-se uma tentativa de compreendê-la a partir de um olhar para as produções científicas que abrangem a área, de modo a inventariálas em dimensão nacional; no segundo, destaca-se um grupo de produções que discutem sobre as políticas públicas e a questão curricular ou práticas educativas da EJA; em um terceiro grupo sobressaem as características historiográficas, que procuram recuperar os fatos históricos relacionados à EJA no Brasil.

Desse percurso da produção acadêmica sobre a EJA no Brasil, a pesquisa de Haddad (1987) destaca-se como um dos primeiros trabalhos a abordar o estado da arte sobre o ensino supletivo no País, a partir da Lei n ${ }^{\circ}$ 5.692/71.

Seu trabalho levantou 31 títulos referentes ao tema, mas selecionou apenas 16 deles para compor a análise, pelo fato de os restantes ou não se caracterizarem como produção

\footnotetext{
${ }^{2}$ Cientes de que, no período compreendido nesta pesquisa, a escolarização do jovem e do adulto no Brasil foi nomeada de maneiras distintas, Ensino Supletivo (até 1996) e Educação de Jovens e Adultos - EJA (após 1996), alertamos o leitor que usaremos o último termo para se referir a todo o período.
} 
acadêmica, (5 documentos oficiais e 2 documentos internos da escola) ou não se conseguir o documento para a análise ( 5 dissertações, 1 pesquisa e 2 artigos de periódicos).

O recorte de pesquisa proposto por Haddad (1987) foram as produções que discutiram o ensino supletivo. Diante disso, os resultados ofereceram indicações preliminares em relação à implantação do ensino supletivo, que, após a promulgação da Lei $n^{\circ}$ 5.692/71, teria ampliado, de forma quantitativa, sistemática e formal, as oportunidades de escolarização de jovens e adultos no Brasil. Entretanto, os dados revelaram também níveis de evasão e repetência extremamente elevados, indicativos de que mecanismos seletivos, identificados no sistema de ensino regular, vinham se reproduzindo na suplência em níveis e intensidade que tinham elementos possíveis de mensurar. A pesquisa aponta indicações preliminares de que os conteúdos curriculares e as metodologias empregadas - ao menos nos cursos e exames de suplência - não se mostraram adequados às necessidades da clientela (HADDAD, 1987).

Nesse contexto, Haddad (2000a) apresenta o resultado de uma pesquisa estado da arte $^{3}$, coordenada pelo pesquisador, de um levantamento da produção discente da pósgraduação em educação no período entre 1986 a 1998, que tematizou a educação de jovens e adultos. O levantamento, caracterizado a princípio como extensivo, compreendeu não só a produção acadêmica stricto sensu, mas toda sorte de publicações, inclusive documentos de órgãos públicos de educação e de organizações não governamentais.

Encontramos trabalhos mais recentes, que descrevem a historicidade da EJA a partir de uma ótica crítica, como a pesquisa de Friedrich et al. (2010), que se caracteriza por uma análise documental da literatura de Educação de Jovens e Adultos e do movimento da modalidade de ensino, políticas públicas, bem como o seu percurso na formação de professores. A pesquisa faz uma comparação com a evolução histórica, com a formação de professores, com o mercado de trabalho no Brasil, a partir das produções acadêmicas e de documentos oficiais como fontes primárias e secundárias de pesquisa, compreendendo o período de 1973 até 2007.

A reflexão histórica de Friedrich et al. (2010) sobre a educação de adultos aponta que essa modalidade é resultado da ineficácia do Estado em garantir, por meio de políticas públicas adequadas, a oferta e a permanência da criança e do adolescente na escola. Para os autores, tais "iniciativas em EJA, em sua grande maioria, caminham na marginalidade do processo educativo brasileiro e as questões mais incisivas no tocante a esta afirmação dizem respeito às propostas de governo criadas de acordo com as necessidades políticas de cada sistema ideologicamente dominante" (FRIEDRICH et al., 2010, p. 405).

Outros estudos, como o de Ribeiro (2001), além da preocupação com a historicidade da EJA no Brasil, apresentaram orientações curriculares referentes à alfabetização e pósalfabetização de jovens e adultos, com propostas para as quatro primeiras séries do ensino fundamental. Segundo Ribeiro (2001), a proposta da obra não foi a de traçar um currículo ou um programa pronto para ser cumprido, mas oferecer subsídios para a formulação de currículos e planos de ensino, que deviam ser desenvolvidos pelos educadores de acordo com as necessidades e objetivos específicos de seus programas.

O estudo de Ribeiro (2001) apontou que a educação de jovens e adultos se caracteriza não só pela diversidade do público que atende e dos contextos social, político e educacional, como pela variedade dos modelos de organização dos programas, mais ou menos formais,

\footnotetext{
${ }^{3}$ Segundo Haddad (2000a, p. 4-5), "foram consultados os catálogos de teses em Educação e o CD-ROM3 produzidos pela Associação Nacional de Pesquisa em Educação (ANPEd) - que trazem a produção de teses e dissertações de 34 instituições que mantêm programas de pós-graduação em educação -, 98 coleções de periódicos nacionais e os anais dos três principais eventos da área 4. Mediante esses procedimentos, apuraram-se mais de 1300 títulos produzidos no período de 1986-1998. Verifica-se que quase 33\% da produção de conhecimento se expressa em artigos de periódicos e números especiais de periódicos, enquanto as teses e dissertações representam aproximadamente $9,5 \%$ da produção total. Os livros ou publicações seriadas publicadas no período representam apenas $7,93 \%$ da produção, o que revela o escasso desenvolvimento editorial da área temática".
} 
mais ou menos extensivos. Descreve a legislação educacional brasileira aberta e flexível quanto à carga horária, à duração e aos componentes curriculares desses cursos, diante do que se observa uma proposta curricular que avança no detalhamento de conteúdos e objetivos educativos, mas permite uma variedade grande de combinações, ênfases, supressões, complementos e formas de concretização.

Estudos que abordam as políticas públicas sobre a EJA e estiveram presentes em dossiês temáticos da Revista Em Aberto, em que se evidenciam as questões das práticas educativas no contexto nacional no ano de 1992, sob a coordenação de Sérgio Haddad (1992), discutiam as tendências da década de noventa na educação de jovens e adultos. Machado (2009, p. 11) sintetiza que esse dossiê apresentou discussões sobre "políticas das organizações internacionais para educação, as políticas para EJA no Brasil, as perspectivas da educação popular na década de 1990, a questão dos jovens e a educação, a educação para os trabalhadores e a política de educação pública popular para jovens e adultos".

Após dezessete anos, a temática das políticas públicas da EJA retorna à Revista Em Aberto sob a organização de Machado (2009). A autora reconhece que a educação de jovens e adultos no Brasil passou por um período de mudanças reveladas por diferentes ações, programas e projetos que, marcados por um arcabouço legal e normativo, revelam outra concepção política e contribuem para uma reconfiguração desse campo educacional. A proposta do dossiê, segundo ela, ao reunir seis artigos que discutem as políticas públicas da EJA em dimensão nacional e internacional, reafirma o direito de todos à educação, conforme previsto na Constituição Federal de 1988, e como modalidade da educação básica, augurada na Lei $\mathrm{n}^{\circ}$ 9.394/96 (MACHADO, 2009).

Sobre as pesquisas na tendência da historiografia, observa-se um enfoque parcial da história da EJA no Brasil, a partir da análise de documentos oficiais, leis e regulamentações ou programas, destacando-se nessa linha as pesquisas de Haddad (1987), Haddad e Di Pierro (2000b), Di Pierro, Joia e Ribeiro (2001), Di Pierro (2004), Galvão e Soares (2004), Ireland, Machado e Paiva (2004).

Logo, tomando como base os estudos apresentados, reconhecemos que a EJA é uma modalidade de ensino muito ampla e que comporta diferentes aspectos, não restritos apenas às práticas de ensino e aprendizagem; há, nos termos freireanos, uma politicidade intrínseca à constituição da educação de jovens e adultos no Brasil. As pesquisas de estado do conhecimento da EJA referenciadas anteriormente mostram diferentes temáticas que essa disciplina ou esse campo de pesquisa e estudos comporta, tais como, entre outros, formação de professores, políticas públicas, concepções e práticas de ensino, educação popular, o perfil do educador e do aluno. Elegemos, para tanto, um recorte das produções acadêmicas sobre EJA, voltando a análise para a alfabetização de jovens e adultos, localizada no âmbito escolar, com intuito de historiografar uma faceta da EJA nas pesquisas realizadas nas universidades brasileiras.

\section{Alfabetização de jovens e adultos nas produções acadêmicas brasileiras}

Na pesquisa realizada no Banco de Teses e Dissertações da Capes e na Biblioteca Digital Brasileira de Teses e Dissertações do IBICT, conseguimos localizar, entre os anos de 1978 e 2000, 65 trabalhos, entre teses e dissertações ${ }^{4}$, com os descritores "alfabetização de

\footnotetext{
${ }^{4}$ Para chegarmos a esse número é importante esclarecer que a pesquisa foi realizada em janeiro de 2019 nos repositórios do Banco de Teses e Dissertações da Capes e na Biblioteca Digital Brasileira de Teses e Dissertações do IBICT. Na CAPES, com os termos "alfabetização de adultos", "alfabetização de jovens" e "alfabetização de jovens e adultos" foram identificados, respectivamente, 16, 30 e 28 trabalhos entre teses e dissertações. No IBICT foram localizados 21 trabalhos com o termo "alfabetização de adultos", 5 designados com a palavra-chave "alfabetização de jovens" e 5 para "alfabetização de jovens e adultos". Adotando os critérios explicitados no decorrer desse artigo e cruzando esses dados, chegamos ao número de 65 teses e dissertações sobre a alfabetização de jovens e adultos defendidas entre 1978 e 2000 em universidades brasileiras.
} 
adultos", "alfabetização de jovens" e "alfabetização de jovens e adultos", conforme a tabela abaixo especifica:

Tabela 1. Quantidade de Dissertações e Teses produzidas por ano (1978-2000)

\begin{tabular}{|cccc|}
\hline Ano & Dissertações & Teses & Total \\
1978 & 1 & 0 & 1 \\
1981 & 1 & 0 & 1 \\
1985 & 1 & 0 & 1 \\
1986 & 0 & 1 & 1 \\
1987 & 1 & 0 & 1 \\
1989 & 1 & 0 & 1 \\
1990 & 3 & 0 & 3 \\
1991 & 3 & 0 & 3 \\
1992 & 2 & 0 & 2 \\
1993 & 3 & 0 & 3 \\
1994 & 3 & 1 & 4 \\
1995 & 1 & 0 & 1 \\
1996 & 2 & 0 & 2 \\
1997 & 4 & 1 & 5 \\
1998 & 12 & 4 & 16 \\
1999 & 8 & 0 & 12 \\
\hline 2000 & 11 & 1 & $\mathbf{6 5}$ \\
\hline Total & $\mathbf{5 7}$ & $\mathbf{8}$ & $\mathbf{1}$ \\
\hline
\end{tabular}

Fonte: Elaborada pelos autores a partir do levantamento na Biblioteca Digital Brasileira de Teses e Dissertações do Instituto Brasileiro de Informação em Ciência e Tecnologia (BDTD-IBICT) e do Catálogo de Teses e Dissertações da Capes.

Para chegarmos a esse número, consideramos para a composição da Tabela 1, apenas as pesquisas que trataram a alfabetização como ensino de leitura e escrita.

Se compararmos o número de 65 trabalhos sobre a alfabetização de jovens e adultos identificados no decurso de 22 anos do século XX com o levantamento realizado por Soares e Maciel (2000), que privilegiou a produção acadêmica acerca da alfabetização de crianças entre 1961 a 1989, notaremos uma diferença substancial, uma vez que as autoras inventariaram 219 pesquisas. Essa diferença incita a algumas reflexões sobre uma tradição que se constituiu nas universidades e na história da educação no Brasil.

A preocupação com o ensino para criança é uma questão histórica no âmbito educacional. Se tomarmos como exemplo as discussões dos presidentes das províncias brasileiras no império, notaremos, como Marcilio (2016) adverte, que havia mais propostas e/ou iniciativas para o ensino de primeiras letras às crianças e adolescentes do que propriamente uma atenção para a educação de jovens e adultos, mesmo que os índices de analfabetismo atingissem a maioria da população brasileira.

As primeiras ações sobre a alfabetização de jovens e adultos no Brasil foram, muitas delas, vinculadas à atuação filantrópica da Igreja ou de grupos missionários. Soares e Galvão (2009, p. 261) acrescentam que houve também, em muitas províncias, a "criação de associações de intelectuais que, entre suas atividades, ministravam cursos noturnos para adultos como uma forma de "regenerar" a massa de pobres [...]".

Embora houvesse uma rede informal de educação doméstica no Império e no início da República, como nos mostram Gondra e Schueler (2008) e Faria Filho e Vidal (2000), consideramos que as ações institucionalizadas de alfabetização de jovens e adultos no Brasil 
surgiram para atender ao processo de industrialização, pelo qual o país passava, e às mudanças provocadas pelo sistema político e econômico instaurado no fim do século XIX.

Com o Ato Adicional de 1834 (BRASIL, 1834), que delegava às províncias a responsabilidade pela instrução primária e secundária, os regulamentos da instrução pública em várias localidades se preocuparam em contemplar a instrução de maiores de 15 anos (SOARES; GALVÃO, 2009). Porém, a primeira escola noturna do Brasil com o objetivo de alfabetizar trabalhadores analfabetos foi aberta em 1854. Paiva (1973) demonstra que a expansão desse modelo escolar se propagou pelas províncias, de modo que no ano de 1874 já estavam em funcionamento 117 escolas noturnas. Em contrapartida, nesse período, a população infantil e juvenil de 6 a 16 anos totalizava 1.902 .454 meninos e meninas, sendo que 320.749 frequentavam uma escola, ou seja 17\% (BRASIL, 1872). Mesmo esse número sendo baixo, ele indica, em relação ao número de escolas noturnas para trabalhadores analfabetos, uma maior quantidade de escolas de primeiras letras para crianças e adolescentes.

Ferraro (2003), fazendo uma história quantitativa da alfabetização no Brasil, mostra que no advento da República, em 1890, mais de $80 \%$ da população era analfabeta. O país promulgava a primeira Constituição da República em 1891, proibindo o voto de quem não sabia ler e escrever. Essa proibição, que por si desvela como se vão configurando no Brasil as políticas de participação democrática e social, retirando direitos de uma parcela considerável do povo, cujo analfabetismo de deve exatamente à negligência do poder público. A educação, indubitavelmente, é um exemplo desses direitos negados ou não privilegiados historicamente.

$\mathrm{Na}$ República, constatados os altos índices de analfabetismo, o governo brasileiro investiu em campanhas nacionais, com certo engajamento voluntário de pessoas para uma alfabetização em massa e num período curto de tempo. Nesse momento, muitos materiais pedagógicos específicos para jovens e adultos foram criados para subsidiar o trabalho dos alfabetizadores. Nos anos 40 e 50, do século XX, Lourenço Filho foi um dos autores de publicações voltadas para alfabetização de adultos e um dos mentores da Campanha de Educação de Adolescentes e Adultos, inaugurada em 1947, uma das primeiras iniciativas do governo republicano para redução do analfabetismo.

Nos fins dos anos 50, houve uma desarticulação das campanhas provocada, especialmente, pelas críticas vindas de Paulo Freire e de seu grupo. Por isso, em 1963 foram extintas, momento em que se constituiu o Plano Nacional de Alfabetização, sancionado pelo Decreto $\mathrm{n}^{\circ}$ 53.465, de 21 de janeiro de 1964 (BRASIL, 1964). A lei instituía um programa para "levar o alfabeto àquelas camadas mais desfavorecidas" que ainda o desconheciam, a partir do uso do "Sistema Paulo Freire" para alfabetização em tempo rápido. Esse programa foi dissolvido em abril de 1964, logo após a instauração do regime ditatorial.

Foi na década de 60, no período da ditadura civil-militar, que houve uma expansão dos projetos de alfabetização de adultos, culminando no Movimento Brasileiro de Alfabetização, o MOBRAL. Extinto em 1985, com a abertura política, esse programa publicou diversos materiais "cartilhados" tanto para o professor, quanto para o aluno.

Ainda no século XX, na década de 90, dois programas de alfabetização de adultos em âmbito nacional podem ser destacados: o MOVA, Movimento de Alfabetização e o Alfabetização Solidária. Ambos de base assistencialista e com vieses teórico-metodológicos em que o analfabeto era visto como um ser incapaz, sem direitos, à margem da sociedade por não dominar a leitura e a escrita.

Como demonstrado, na história da educação brasileira a temática da alfabetização de jovens e adultos foi um aspecto muito marginal nos debates políticos e nas legislações. A preocupação estava muito centralizada na alfabetização de crianças. De certa maneira, ao retomarmos a Tabela 1, a princípio, a primeira impressão é que nas pesquisas acadêmicas no âmbito da universidade há um reflexo dessa questão histórica, da não evidência do sujeito analfabeto adulto nas iniciativas governamentais. Porém, se olharmos o número de programas 
de pós-graduação existentes no período em questão, 1978 a 2000, e o fato do reconhecimento da educação de jovens e adultos como modalidade de ensino somente em 1996, redirecionamos o nosso olhar, confirmando a hipótese de que a temática da alfabetização de jovens e adultos tem um lugar específico e plural nas pesquisas produzidas nas universidades brasileiras no século XX.

O número de 65 produções acadêmicas é reduzido em relação aos dados de Maciel (2014), que catalogou 949 teses e dissertações sobre alfabetização de crianças entre as décadas de 1970 e 1990. Todavia, esse número pode ser melhor compreendido ao olharmos para a própria questão da EJA nos cursos de Licenciatura do Brasil. A pesquisa coordenada por Gatti e Barretto (2009), ao analisar, na primeira década do século XXI, uma avolumada quantidade de ementas de cursos superiores de formação inicial dos professores brasileiros, mostra a marginalização da EJA, enquanto disciplina na universidade, inserida muitas vezes no núcleo das optativas ou até mesmo ausente das suas matrizes curriculares. Mesmo que os dados de Gatti e Barretto (2009) não revelem diretamente aspectos do período histórico desse trabalho, eles demonstram a pouca repercussão dos temas relativos à educação de jovens e adultos nos primeiros anos do século XXI, mesmo depois de ter sido reconhecida como modalidade de ensino em 1996.

A pesquisa de Di Pierro (2011) atualizou os levantamentos de estado da arte sobre a educação de jovens e adultos no Brasil, num balanço das teses e dissertações sobre formação de educadores na EJA, publicizadas entre 1971 e 2008, apontando que, nas instituições de ensino superior, predominaram estudos sobre a formação continuada do educador de jovens e adultos, uma vez que as ações voltadas a atender essa especificidade da formação do professor estavam mais nas atividades de extensão do que nas de ensino ou pesquisa.

Todos esses dados, evidentemente, repercutem nas estatísticas de produções acerca do tema que estamos debatendo nesse trabalho. Mesmo sendo pequena a quantidade de teses e dissertações produzidas sobre a alfabetização de jovens e adultos no final do século XX, consideramos que elas representam o início de um campo de estudos e pesquisas, arquitetado com características próprias e marcos teórico-metodológicos também muito distintivos, como avaliaremos adiante.

Outro ponto importante a considerar é a ampliação de pesquisas sobre a alfabetização de jovens e adultos nos anos 90 , como condensamos na tabela a seguir:

Tabela 2. Quantidade de Dissertações e Teses produzidas por décadas (1978-2000)

\begin{tabular}{|cccc|}
\hline Décadas & Dissertações & Teses & Total \\
$1978-1979$ & 1 & 0 & 1 \\
$1980-1989$ & 4 & 1 & 5 \\
$1990-1999$ & 41 & 6 & 47 \\
2000 & 11 & 1 & 12 \\
Total & $\mathbf{5 7}$ & $\mathbf{8}$ & $\mathbf{6 5}$ \\
\hline
\end{tabular}

Fonte: Elaborada pelos autores a partir do levantamento na Biblioteca Digital Brasileira de Teses e Dissertações do Instituto Brasileiro de Informação em Ciência e Tecnologia (BDTD-IBICT) e do Catálogo de Teses e Dissertações da Capes.

O crescimento de produções acadêmicas, nos anos 90, relaciona-se à difusão de programas de pós-graduação em educação nas variadas regiões do país. Também é nessa década que há mais defesas de teses de doutorado. Esse dado coincide com a pesquisa de Maciel (2014) sobre alfabetização infantil; a autora mostra que nesse período há um crescimento na produção de pesquisas de mestrado e doutorado cuja temática é a alfabetização. Sobre essa situação, Mortatti, Oliveira e Pasquim (2014) explicam que, especialmente após a década de 1990, há a intensificação de denúncias acerca dos problemas 
da educação e "a alfabetização ganha destaque como um dos fatores prioritários na definição de compromissos e metas globais, estabelecidos por organismos multilaterais" (MORTATTI; OLIVEIRA; PASQUIM, 2014, p. 12). Os autores lembram que nessa década houve iniciativas emblemáticas em âmbito mundial no campo da alfabetização, que podem ter induzido pesquisas no contexto acadêmico: a Declaração do "Ano Internacional da Alfabetização" (1990) e a Declaração de Jomtien (1990).

Como evidenciado na tabela $2,88 \%$ dos trabalhos produzidos são dissertações de mestrado, e apenas 12\%, teses de doutorado. De igual maneira, Maciel (2014), no seu levantamento sobre alfabetização de crianças, indica a disparidade entre o número de produções em teses e dissertações, numa proporção de 4,7 dissertações para uma tese.

Enfim, do que trataram essas pesquisas? Onde foram produzidas? O que elas revelam sobre a história da alfabetização de jovens e adultos no Brasil?

\section{Lugares e temáticas das produções acadêmicas brasileiras sobre alfabetização de jovens e adultos}

Ao tratarmos sobre os lugares de uma pesquisa, delimitamos o espaço onde foi produzida e/ou ao qual se refere. Olhando cada uma das 65 produções acadêmicas inventariadas anteriormente, foi possível quantificar, por universidade, o número de teses e dissertações produzidas:

Tabela 3. Quantidade de Dissertações e Teses produzidas sobre alfabetização de jovens e adultos por universidade entre 1978-2000

\begin{tabular}{|lcccc|}
\hline \multicolumn{1}{c}{ Categoria Temática } & Dissertações & Teses & Total \\
Fundação Getúlio Vargas (FGV) & 5 & 0 & 5 \\
Pontifícia Universidade Católica de Campinas (PUC-Campinas) & 1 & 0 & 1 \\
\hline Pontifícia Universidade Católica de Minas Gerais (PUC Minas) & 1 & 0 & 1 \\
Pontifícia Universidade Católica do Rio de Janeiro (PUC-Rio) & 2 & 0 & 2 \\
Pontifícia Universidade Católica do Rio Grande do Sul (PUCRS) & 4 & 0 & 4 \\
Pontifícia Universidade Católica de São Paulo (PUC-SP) & 4 & 1 & 5 \\
Universidade do Estado do Rio de Janeiro (UERJ) & 1 & 0 & 1 \\
Universidade Federal da Bahia (UFBA) & 1 & 0 & 1 \\
Universidade Federal do Ceará (UFC) & 1 & 0 & 1 \\
Universidade Federal Fluminense (UFF) & 3 & 0 & 3 \\
Universidade Federal do Mato Grosso (UFMT) & 1 & 0 & 1 \\
Universidade Federal da Paraíba (UFPB) & 6 & 0 & 6 \\
Universidade Federal de Pernambuco (UFPE) & 2 & 1 & 3 \\
Universidade Federal do Rio Grande do Sul (UFRGS) & 4 & 0 & 4 \\
Universidade Federal do Rio Grande do Norte (UFRN) & 1 & 0 & 1 \\
Universidade Federal de Santa Catarina (UFSC) & 3 & 1 & 4 \\
Universidade de Brasília (UnB) & 5 & 0 & 5 \\
Universidade Estadual Paulista “Júlio de Mesquita Filho" (UNESP) & 0 & 1 & 1 \\
Universidade Estadual de Campinas (UNICAMP) & 6 & 2 & 8 \\
Universidade Católica de Brasília (UCB) & 3 & 0 & 3 \\
\hline Universidade de Passo Fundo (UPF) & 1 & 0 & 1 \\
Universidade Metodista de Piracicaba (UNIMEP) & 2 & 0 & 2 \\
\hline Universidade de São Paulo (USP) & 0 & 2 & 2 \\
\hline & $\mathbf{5 7}$ Total & $\mathbf{8}$ & $\mathbf{6 5}$ \\
\hline
\end{tabular}

Fonte: Elaborada pelos autores a partir do levantamento na Biblioteca Digital Brasileira de Teses e Dissertações do Instituto Brasileiro de Informação em Ciência e Tecnologia (BDTD-IBICT) e do Catálogo de Teses e Dissertações da Capes. 
As 65 produções acadêmicas identificadas são advindas de 23 universidades, sendo $48 \%$ destas da região Sudeste, $20 \%$ da região Sul, $18 \%$ da região Nordeste e $14 \%$ da região Centro-oeste. Até o momento não encontramos nenhuma dissertação ou tese referente à alfabetização de jovens e adultos produzida em universidade da região Norte no século XX. $\mathrm{O}$ Sudeste destaca-se, também, no número de programas de pós-graduação em educação e, consequentemente, detém, segundo os dados do Banco de Teses e Dissertações da Capes, mais de $40 \%$ das produções acadêmicas defendidas até o final do século XX nas universidades brasileiras. Vale frisar que o primeiro programa de pós-graduação em educação do Brasil tem origem nessa região, no Rio de Janeiro, em 1965, o que também colabora para um número acentuado de produções do Sudeste em relação às demais regiões brasileiras.

Saindo do espaço onde as teses e dissertações foram produzidas, passando aos seus conteúdos, foi possível mapear os lugares aos quais as pesquisas se referem, organizando um panorama dos estados que têm investigações sobre alfabetização de jovens e adultos no século $\mathrm{XX}$, conforme registrado na Tabela 4.

Tabela 4. Estados brasileiros sobre os quais as Dissertações e Teses produzidas entre 1978 e 2000 trataram da temática da alfabetização de jovens e adultos.

\begin{tabular}{|cccc|}
\hline Estado & Dissertações & Teses & Total \\
\hline Amazonas & 1 & 0 & 1 \\
Bahia & 1 & 0 & 1 \\
Ceará & 1 & 0 & 1 \\
\hline Distrito Federal & 8 & 1 & 9 \\
Goiás & 2 & 0 & 2 \\
Mato Grosso & 1 & 0 & 1 \\
Minas Gerais & 1 & 0 & 1 \\
Paraíba & 5 & 0 & 5 \\
Pernambuco & 2 & 1 & 3 \\
Rio de Janeiro & 8 & 0 & 8 \\
Rio Grande do Norte & 2 & 1 & 3 \\
Rio Grande do Sul & 9 & 0 & 1 \\
Rondônia & 1 & 0 & 3 \\
Santa Catarina & 3 & 0 & 17 \\
São Paulo & 12 & 5 & 1 \\
Brasil & 1 & 0 & $\mathbf{6 6}$ \\
\hline Total & $\mathbf{5 8}$ & $\mathbf{8}$ & 9 \\
\hline
\end{tabular}

Fonte: Elaborada pelos autores a partir do levantamento na Biblioteca Digital Brasileira de Teses e Dissertações do Instituto Brasileiro de Informação em Ciência e Tecnologia (BDTD-IBICT) e do Catálogo de Teses e Dissertações da Capes.

De imediato, é preciso esclarecer ao leitor que o total de produções acadêmicas resultou em 66 trabalhos, pois uma dissertação localizada fez referência a dois estados brasileiros. Ao indicarmos os estados, novamente notamos a superioridade do número de produções sobre a região Sudeste, com destaque para São Paulo. Entretanto, não há uma total convergência entre o lugar (universidade) onde as pesquisas foram defendidas e o lugar (estado) a que se referiam, já que sobre a região Sudeste foram 26 produções acadêmicas, totalizando $40 \%$. Subsequentemente, estão a região Nordeste com 21\%; Sul e Centro-Oeste com $18 \%$ cada uma; e o Norte com 1,5\%. Na tabela há uma dissertação que se referiu ao Brasil como um todo, perfazendo um percentual de 1,5\% dos trabalhos inventariados. Essa informação dialoga com um fenômeno muito comum no Brasil no decorrer do século XX e início do século XXI, antes 
da expansão e democratização do ensino superior ${ }^{5}$, quando muitos pesquisadores deslocavam-se da sua localidade para realizar seu Mestrado ou Doutorado em regiões que ofereciam esses cursos e geralmente faziam suas pesquisas sobre os lugares de onde vinham.

É importante referenciar que essas produções acadêmicas foram advindas de programas de pós-graduação de áreas distintas, sendo preponderante a Educação, com $71 \%$ das teses e dissertações; em seguida Letras e Linguística, com 17\%; Psicologia e Ciências da Informação, cada um com 3\%; por fim, os programas de História, Ciências Políticas, Ciências Sociais e Ciências da Comunicação, com 1,5\% cada um. Esses dados mostram que a temática "alfabetização de jovens e adultos" circulava em outros campos de conhecimento que, de certa forma, fazem interface com a área educacional. De igual forma, na pesquisa de Soares (1989) sobre o estado de conhecimento da alfabetização de crianças até a década de 80 do século XX, a autora já demonstrava a vinculação das pesquisas às áreas da Educação, Letras e Psicologia.

Com relação aos temas privilegiados nos trabalhos sobre alfabetização de jovens e adultos no Brasil do século XX, a leitura das teses e dissertações nos permitiu criar algumas categorias que possibilitaram a organização de um panorama dos conhecimentos produzidos no período de 1978 a 2000.

Tabela 5. Quantidade de Dissertações e Teses por categoria temática (1978-2000)

\begin{tabular}{|c|c|c|c|}
\hline $\begin{array}{l}\text { Categoria Temática } \\
\end{array}$ & Dissertações & Teses & Total \\
\hline Aspectos históricos da alfabetização de jovens e adultos & 1 & 1 & 2 \\
\hline Aspectos linguísticos da alfabetização de jovens e adultos & 6 & 2 & 8 \\
\hline Aspectos cognitivos da alfabetização de jovens e adultos & 0 & 1 & 1 \\
\hline Estudo sobre bases teóricas da alfabetização de jovens e adultos & 3 & 1 & 4 \\
\hline Formação do professor alfabetizador de jovens e adultos & 7 & 0 & 7 \\
\hline Literatura no processo de alfabetização de jovens e adultos & 1 & 0 & 1 \\
\hline $\begin{array}{l}\text { Políticas de alfabetização de jovens e adultos - programas, } \\
\text { projetos, iniciativas governamentais e não governamentais }\end{array}$ & 16 & 0 & 16 \\
\hline Representações sobre a alfabetização de jovens e adultos & 9 & 1 & 10 \\
\hline Vivências de alfabetização de jovens e adultos & 14 & 2 & 16 \\
\hline Total & 57 & 8 & 65 \\
\hline
\end{tabular}

Fonte: Elaborada pelos autores a partir do levantamento na Biblioteca Digital Brasileira de Teses e Dissertações do Instituto Brasileiro de Informação em Ciência e Tecnologia (BDTD-IBICT) e do Catálogo de Teses e Dissertações da Capes.

Para estabelecermos essas categorias temáticas, alguns critérios foram adotados. $\mathrm{O}$ primeiro deles se referiu à aproximação dos trabalhos por certas individualidades (temas e aspectos teórico-metodológicos) que os distinguiam uns dos outros. O segundo critério foi de estabelecer cada categoria pensando no momento histórico em que os trabalhos foram escritos, sem anacronismos. Por fim, para constituir uma categoria, mesmo que o número de trabalhos sobre o tema fosse pequeno, fizemos a opção por criar um tópico independente, para dar visibilidade às temáticas e pesquisas que estiveram nas bases da constituição do campo da alfabetização de jovens e adultos. Exemplo disso são as categorias "aspectos cognitivos da alfabetização de jovens e adultos" e "literatura no processo de alfabetização de jovens e adultos".

Sobre a primeira, catalogamos apenas o trabalho de Tfouni (1986), que objetivou explicitar aspectos do funcionamento cognitivo em um grupo de analfabetos brasileiros. Ancorando-se em procedimentos linguísticos, mas com uma abordagem central de base nos estudos da Psicologia, a autora concluiu que uma das contribuições de seu trabalho foi que a lógica da análise dos processos cognitivos dos sujeitos não alfabetizados, naquele momento, poderia ser mudada. Em contraposição a algumas teorias psicológicas, Tfouni (1986, p. 216)

\footnotetext{
${ }^{5}$ Sobre essa questão, cf.: Cirani, Campanario e Silva (2015).
} 
fez uma análise que tomava "o sujeito do discurso e a enunciação como lugares privilegiados onde o funcionamento intelectual (também) pode ser detectado e investigado". A tese de doutorado de Tfouni (1986), publicada em formato de livro em 1988 pela Editora Pontes, foi um marco nos estudos do letramento no Brasil, pois, segundo Soares (1998, p. 15), talvez seja com esse trabalho que "letramento ganha estatuto de termo técnico no léxico dos campos da Educação e das Ciências Linguísticas"6.

A segunda categoria com menor recorrência de produções acadêmicas e que destacamos como um tópico específico, foi a que trata da literatura no processo de alfabetização de jovens e adultos. A dissertação de Silva (1999) foi a única identificada que abordou a formação do leitor literário nos cursos de alfabetização de jovens e adultos. A leitura esteve presente em outras produções acadêmicas, mas, nesse trabalho, vimos pela primeira vez, a terminologia "formação do leitor literário adulto". A partir de uma pesquisaação, Silva (1999) analisa os papéis que a literatura desempenhou no processo de formação do leitor adulto.

As temáticas com maior incidência pela leitura da Tabela 5 foram sobre as "políticas de alfabetização de jovens e adultos" e o que denominamos de "vivências de alfabetização de jovens e adultos". Ao analisar e categorizar os trabalhos nessas categorias, notamos a vinculação das iniciativas de alfabetização de jovens e adultos com aspectos políticos no decorrer da história da educação no Brasil. Sobre isso, um dado importante que não passa imperceptível nas teses e dissertações no século XX é a presença avolumada das referências ao educador Paulo Freire.

Das 65 dissertações e teses inventariadas, conseguimos ter acesso ao texto completo de 35. Desse total, 18 pesquisas citaram Paulo Freire nas referências bibliográficas. Vale frisar que, mesmo nos trabalhos que não fizeram menção à obra de Paulo Freire na bibliografia, notamos as ideias do autor presentes, por meio de escritos de outros autores que se apoiavam em Freire para debater questões relacionadas à educação e à alfabetização de jovens e adultos. Outro aspecto importante a considerar é que em muitos dos trabalhos cujos textos completos não localizamos havia menção às ideias freireanas e ao "método" Paulo Freire no resumo disponibilizado nos repositórios das universidades, o que também demonstra a influência de Freire nas bases de uma corrente teórica e metodológica, genuinamente brasileira, que constituiu uma pedagogia de educação popular para alfabetização de jovens e adultos no Brasil, influenciando os modos de conceber e atuar com esse público nas escolas.

\section{Conclusões}

Ao tomar as produções acadêmicas como fonte histórica de análise, foi possível compreender aspectos da história da alfabetização de jovens e adultos no Brasil, a partir dos discursos acadêmicos produzidos no período de 1978 a 2000. O estudo nos mostra uma produção em ascensão, tendo, na década de 90 , um volume mais adensado, demonstrado numa preocupação da academia de desenvolver pesquisas sobre o tema alfabetização de adultos, sendo o ano de 1998 o de maior produção sobre o tema. Tal questão pode ser justificada se tomarmos como referência as mudanças ocorridas na década de 90 no âmbito da legislação educacional, quando houve a promulgação da Lei de Diretrizes e Bases da Educação Nacional n. ${ }^{\circ}$ 9.394/1996, em que a Educação de Jovens e Adultos foi reconhecida como uma modalidade de ensino. Esse aspecto legal influenciou diretamente na produção acadêmica, já que, após a aprovação dessa lei, entre 1997 a 2000, concentram-se 41 dos 65 trabalhos identificados sobre a alfabetização de jovens e adultos, o que corresponde a mais de 50\% das teses e/ou dissertações defendidas nas universidades brasileiras no período pesquisado.

\footnotetext{
${ }^{6}$ Sobre a história do termo letramento no Brasil, cf. Mortatti (2004). Nesse livro, inclusive, Mortatti faz alusão ao trabalho de Tfouni (1986), nas balizas da teorização do termo letramento no Brasil.
} 
Um aspecto importante a considerar se refere às temáticas das pesquisas pós-LDBEN. Houve um aumento das produções acadêmicas sobre as políticas públicas da EJA, como também das ações, representações e vivências de alfabetização de jovens e adultos. Observamos, ainda, uma diversidade temática; nesse período foi possível deparar com pesquisas que se preocupavam com a discussão das bases teóricas da educação de jovens e adultos. Outro ponto que nos chamou atenção, analisando as teses e dissertações no período de 1997 a 2000, foi o recorrente debate sobre a formação do alfabetizador do jovem e adulto. Já havia pesquisas que especificamente tratavam dessa temática, mas passou a haver referência a ela em praticamente todos os trabalhos defendidos pós-LDBEN.

A publicação "O estado da arte das pesquisas em educação de jovens e adultos no Brasil" (HADDAD, 2000a) aponta que, nas questões relativas aos aportes teóricos das pesquisas em EJA, percebe-se ainda uma grande dispersão entre os autores utilizados, havendo alguma unidade nas referências históricas da EJA e uma grande utilização do pensamento de Paulo Freire, tanto no que se refere às práticas, quanto à formação dos professores. As demais reflexões encontram-se dispersas em diversos referenciais.

Ao analisar as 65 produções acadêmicas inventariadas e analisadas no decorrer deste artigo, observamos que a temática alfabetização de jovens e adultos passou a constituir um campo específico de pesquisas no Brasil do século XX, na medida que houve preocupação da universidade em investigar os processos de ensino e aprendizagem do público jovem e adulto, tendo então se iniciado a constituição de um aparato teórico-metodológico para essas investigações. Esse campo também pode ser denominado plural, pois as temáticas e abordagens, como vimos, não são unívocas, mas multifacetadas.

Algumas lacunas, evidentemente, podem ser apreendidas a partir do balanço das produções acadêmicas. A primeira delas é com relação ao entrecruzamento, no século XX, de ações, projetos, programas e iniciativas governamentais em âmbito nacional com iniciativas em âmbito local (municipal ou estadual). Notamos a ausência de pesquisas que, contrapondo essas políticas de educação, em nível macro e micro, alertassem ou propusessem mudanças na alfabetização de jovens e adultos no Brasil. O que vimos, geralmente, foram avaliações de práticas, sem muitas propostas para reversão do quadro e do estigma do analfabetismo entre a população adulta brasileira.

Outra lacuna foi com relação à presença das pesquisas sobre a escrita na alfabetização de jovens e adultos. A maioria das investigações se concentraram no ensino e no aprendizado da leitura, sem dar muita ênfase aos processos de escrita, como se a alfabetização estivesse restrita ao ato de ler. Via de regra, no Brasil, como nos explica Soares (2016), historicamente a leitura foi contemplada como objeto privilegiado no processo de alfabetização; com frequência, até os anos de 1980, falava-se em métodos de leitura e livros para o ensino de leitura. "A bibliografia sobre a aprendizagem inicial da língua escrita, durante quase todo o século XX, refere-se predominantemente ao ensino da leitura; até mesmo nas definições de dicionários para termos relativos à alfabetização a leitura é privilegiada" (SOARES, 2016, p. 25).

Outra lacuna visível é a de trabalhos voltados para a história da EJA. Identificamos apenas duas pesquisas sobre os aspectos históricos da alfabetização de jovens e adultos. Essa categoria temática, que não foi priorizada no século $\mathrm{XX}$, incita a novos olhares e novos objetos de estudos tanto para pensar a produção científica sobre ela no século XXI, quanto para analisar a permanência histórica do fenômeno do analfabetismo nos índices de educação brasileira. Afinal, de fato, "para a concepção crítica, o analfabetismo não é uma 'chaga', nem uma 'erva daninha' a ser erradicada, nem tampouco uma enfermidade, mas uma das expressões concretas de uma realidade social injusta” (FREIRE, 1981, p. 13). 


\section{Referências}

BRASIL. Decreto $n^{0}$ 53.465, de 21 de janeiro de 1964. Institui o Programa Nacional de Alfabetização do Ministério da Educação e Cultura e dá outras providências. Disponível: <http://www2.camara.leg.br/legin/fed/decret/1960-1969/decreto-53465-21-janeiro-1964-3935 08-publicacaooriginal-1-pe.html>. Acesso em: 13 jan. 2019.

BRASIL. FUNDO NACIONAL DE DESENVOLVIMENTO DA EDUCAÇÃO. Resolução n. 51 de 16 de setembro de 2009. Dispõe sobre o programa do Livro Didático para Educação de Jovens e Adultos (PNLD EJA). Disponível em: <http://portal.mec.gov.br/ index.php?option=com_docman\&view=download\&alias=10026-resolucao-512009secadi \& category_slug=fevereiro-201 2-pdf\&Itemid=30192>. Acesso em: 10 jan. 2019.

BRASIL. Lei Imperial de n. ${ }^{\circ}$ 40, de 3 de outubro de 1834. Dispõe sobre o poder do presidente de província. Coleção de Leis Império do Brasil do ano de 1834. Rio de Janeiro: Typographia Nacional, 1866.

BRASIL. Recenseamento do Brazil em 1872. Disponível em: <https://biblioteca.ibge.gov.br/ visualizacao/monografias/GEBIS\%20\%20RJ/Recenseamento_do_Brazil_1872/Imperio\%20d o\%20Brazil\%201872.pdf>. Acesso em: 10 jan. 2019.

BRASIL. Lei n. ${ }^{\circ}$ 5.692, de 11 de agosto de 1971. Fixa as Diretrizes e Bases para o Ensino de $1^{\circ}$ e $2^{\circ}$ graus, e dá outras providências. Disponível em: <http://www2.camara.leg.br/legin/f ed/lei/1970-1979/lei-5692-11-agosto-1971-357752-publicacaooriginal-1-pl.html>. Acesso em: 11 jan. 2019.

BRASIL. Lei no 9394 de 20 dezembro de 1996. Estabelece as Diretrizes e Bases da Educação Nacional. Diário Oficial da União, Brasília, p. 027833, col. 1, 23 dez. 1996.

BRASIL. Ministério da Educação. Diretrizes curriculares nacionais para a educação de jovens e adultos. Brasília: MEC, 2000.

CERTEAU, Michel de. A escrita da História. Tradução de Maria de Lourdes Menezes. 2. ed. Rio de Janeiro: Forense Universitária, 2010.

DI PIERRO, Maria Clara. Um balanço da evolução recente da educação de jovens e adultos no Brasil. Alfabetização \& Cidadania, São Paulo, v. 17, p.11-23, 2004.

DI PIERRO, Maria Clara. Balanço e perspectivas da pesquisa sobre formação de educadores de jovens e adultos. In.: OLIVEIRA, E. F. et al (Orgs.). Anais do $3^{\mathbf{0}}$ Seminário Nacional de Formação de Educadores. Porto Alegre: Deriva, 2011.

DI PIERRO, Maria Clara; JOIA, Orlando; RIBEIRO, Vera Masagão. Visões da educação de jovens e adultos no Brasil. Caderno Cedes, Campinas, SP, n. 55, p. 58-77. 2001. https://doi.org/10.1590/S0101-32622001000300005

FARIA FILHO, Luciano Mendes de; VIDAL, Diana Gonçalves. Os tempos e os espaços escolares no processo de institucionalização da escola primária no Brasil. Revista Brasileira de Educação, n. ${ }^{\circ}$ 4, p. 19-34, Mai./Jun./Ago. 2000. 
FERRARO, Alceu Ravanello. História quantitativa da alfabetização no Brasil. In: RIBEIRO, Vera Masagão (Org.). Letramento no Brasil. São Paulo: Global, 2003.

FREIRE, Paulo. Ação cultural para a liberdade. 5. Ed. Rio de Janeiro: Paz e Terra, 1981.

FRIEDRICH, Márcia; BENITE, Anna M. Canavarro; BENITE, Claudio R. Machado; PEREIRA; Viviane Soares. Trajetória da escolarização de jovens e adultos no Brasil: de plataformas de governo a propostas pedagógicas esvaziadas. Ensaio: Avaliação Política Pública Educacional, Rio de Janeiro, v. 18, n. 67, p. 389-410, abr.jun. 2010.

https://doi.org/10.1590/S0104-40362010000200011

GALVÃO, Ana Maria de Oliveira; SOARES, Leôncio. História da alfabetização de adultos no Brasil. In: ALBUQUERQUE, Eliana Borges Correia de; LEAL, Telma Ferraz (Orgs.). A alfabetização de jovens e adultos em uma perspectiva de letramento. Belo Horizonte: Autêntica, 2004.

GATTI, Bernadete Angelina; BARRETO, Elba Siqueira de Sá (Coords.). Professores do Brasil: impasses e desafios. Brasília: UNESCO, 2009.

GONDRA, José Gonçalves; SCHUELER, Alessandra. Educação, poder e sociedade no Império brasileiro. São Paulo: Cortez, 2008.

HADDAD, Sérgio. Ensino Supletivo no Brasil: o estado da arte. Brasília: REDUC/INEP, 1987.

HADDAD, Sérgio. Tendências atuais na educação de jovens e adultos. Revista Em Aberto, Brasília, out./dez. 1992, vol. 11, no 4, p. 3-12.

HADDAD, Sérgio. (Org.). O estado da arte das pesquisas em educação de jovens e adultos no Brasil. A produção discente da pós-graduação em educação no período 1986 1998. São Paulo: Associação Educativa, 2000a.

HADDAD, Sérgio; DI PIERRO, M. C. Escolarização de jovens e adultos. Revista Brasileira de Educação, São Paulo, n. 14, p. 108-130, 2000 b.

IRELAND, Timothy.; MACHADO, Maria Margarida; PAIVA, Jane (Orgs.). Educação de jovens e adultos: uma memória contemporânea (1996-2004). Brasília, DF: UNESCO/MEC, 2004.

MACHADO, Maria Margarida (Org.). Educação de jovens e adultos. Revista Em Aberto, Brasília, v. 22, n. 82, p. 1-147, nov. 2009.

MACIEL, Francisca Izabel Pereira. Alfabetização no Brasil: pesquisas, dados e análise. In: MORTATTI, Maria do Rosário Longo; FRADE, Isabel Cristina Alves da Silva (Orgs.). Alfabetização e seus sentidos: o que sabemos, fazemos e queremos? Marília: Oficina Universitária; São Paulo: Editora UNESP, 2014.

MARCILIO, Maria Luiza. História da alfabetização no Brasil. São Paulo: EdUSP, 2016.

MORTATTI, Maria do Rosário Longo. Educação e letramento. São Paulo: UNESP, 2004. 
MORTATTI, Maria do Rosário Longo; OLIVEIRA, Fernando Rodrigues de; PASQUIM, Franciele Ruiz. 50 anos de produção acadêmica brasileira sobre alfabetização: avanços, contradições e desafios. Interfaces da Educação, Paranaíba, v. 5, n. ${ }^{\circ}$ 13, p. 6-31, 2014.

PAIVA, Vanilda Pereira. Educação popular e educação de adultos. São Paulo: Loyola 1973.

RIBEIRO, Vera Maria Masagão (Org.). Educação para jovens e adultos: ensino fundamental: proposta curricular $1^{\circ}$ segmento. São Paulo: Ação Educativa; Brasília: MEC, 2001.

SILVA, Simone Bueno Borges da. Leitura, Literatura e Alfabetização de Adultos. 1999. 189 p. Dissertação (Mestrado em Linguística Aplicada) - Universidade Estadual de Campinas, Campinas, 1999.

SOARES, Leôncio; GALVÃO, Ana Maria de Oliveira. Uma história da alfabetização de adultos no Brasil. In: STEPHANOU, Maria; BASTOS, Maria Helena Camara (Orgs.). Histórias e Memórias da Educação no Brasil - Século XX. Vol. 3. 3. ed. Petrópolis, RJ: Vozes, 2009.

SOARES, Magda. Alfabetização no Brasil: o estado do conhecimento. Brasília, DF: INEP; Santiago: REDUC, 1989.

SOARES, Magda. Letramento: um tema em três gêneros. Belo Horizonte: Autêntica, 1998.

SOARES, Magda. Alfabetização: a questão dos métodos. São Paulo: Contexto, 2016.

SOARES, Magda; MACIEL, Francisca Izabel Pereira. Alfabetização no Brasil: o estado do conhecimento. Brasília, DF: MEC/INEP/COMPED, 2000.

TFOUNI, Leda Maria V. Adultos não-alfabetizados: o avesso do avesso. 1986. 240 f. Tese (Doutorado em Linguística) - Universidade Estadual de Campinas, Campinas, 1986.

TFOUNI, Leda Maria V. Adultos não alfabetizados: o avesso do avesso. Campinas: Pontes, 1988. 